\title{
Impact of chill storage on antioxidant status, lipid and protein oxidation, color, drip loss and fatty acids of semimembranosus muscle in goats
}

\begin{abstract}
The study examined the effect of refrigerated storage on antioxidant activities, lipid and protein oxidation, fatty acids (FAs), drip loss and color of semimembranosus (SM) muscle from goats. Samples of SM were obtained from carcasses of 15 Boer bucks (7 months old; body weight, $32.18 \pm 0.81 \mathrm{~kg}$ ) subjected to an $8 \mathrm{~d}$ storage at $4^{\circ} \mathrm{C}$. Superoxide dismutase (SOD), catalase (CAT) and glutathione peroxidase (GPX) activities were stable while carotenoid, tocopherol, water holding capacity and redness declined $(\mathrm{P}<0.05)$ as storage progressed. Carbonyl content increased from 1.85 to $4.73 \mathrm{nmol} / \mathrm{mg}$ protein while thiol content reduced from 54.22 to $42.82 \mathrm{nmol} / \mathrm{mg}$ protein. The TBARS value increased from 0.2 to $0.8 \mathrm{mg} \mathrm{MDA} / \mathrm{kg}$. SDS-PAGE expression of myosin heavy chain (MHC) decreased (P < $0.05)$ from 72.45 to 49.82 density/mm2 while actin reduced $(\mathrm{P}>0.05)$ from 14.00 to 13.08 density/mm2. The concentrations of $n-3$ and n- 6 FA decreased while the saturated FA increased over storage. Correlations $(\mathrm{P}<0.05)$ were found between antioxidant vitamins and quality indicators of chevon.
\end{abstract}

Keyword: Actin; Catalase; Carbonyl; Glutathione peroxidase; Myosin; Thiol; Superoxide dismutase 